\title{
Combretastatin A-4 Analogue: A Dual-targeting and Tubulin Inhibitor Containing Antitumor Pt(IV) Moiety with a Unique Mode of Action
}

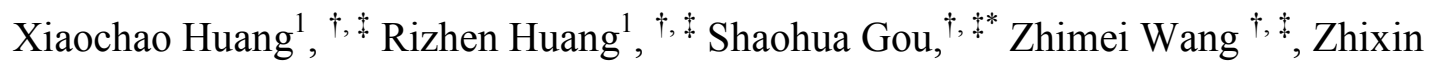
Liao, ${ }^{\dagger}{ }^{\ddagger}$ and Hengshan Wang ${ }^{\S, *}$

'Pharmaceutical Research Center and School of Chemistry and Chemical Engineering, Southeast University, Nanjing 211189, PR China

${ }^{*}$ Jiangsu Province Hi-Tech Key Laboratory for Bio-medical Research, Southeast University, Nanjing 211189, PR China

${ }^{\S}$ State Key Laboratory for the Chemistry and Molecular Engineering of Medicinal Resources (Ministry of Education of China), School of Chemistry and Pharmaceutical Sciences of Guangxi Normal University, Guilin 541004, PR China

1. The released ability of Pt(IV) complexes under reduction with ascorbic acid.
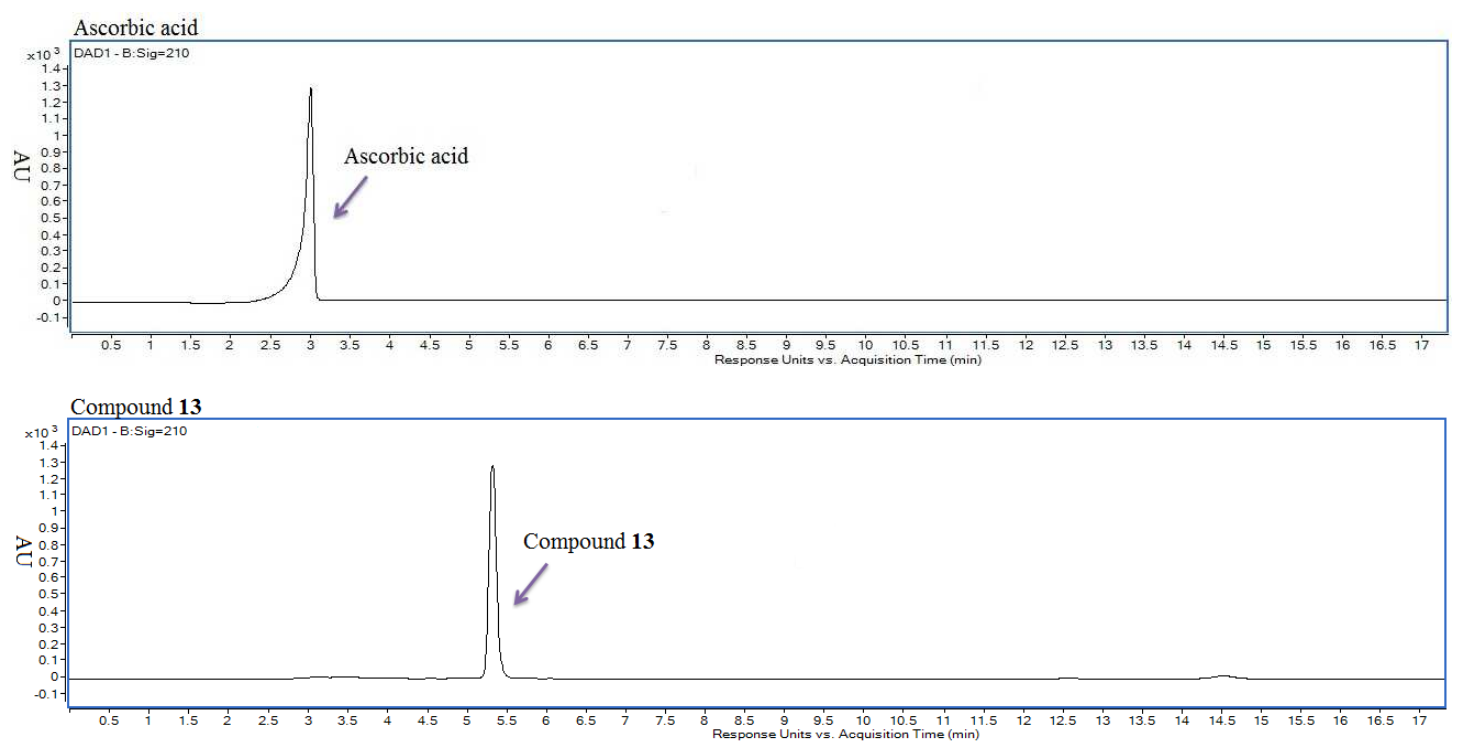


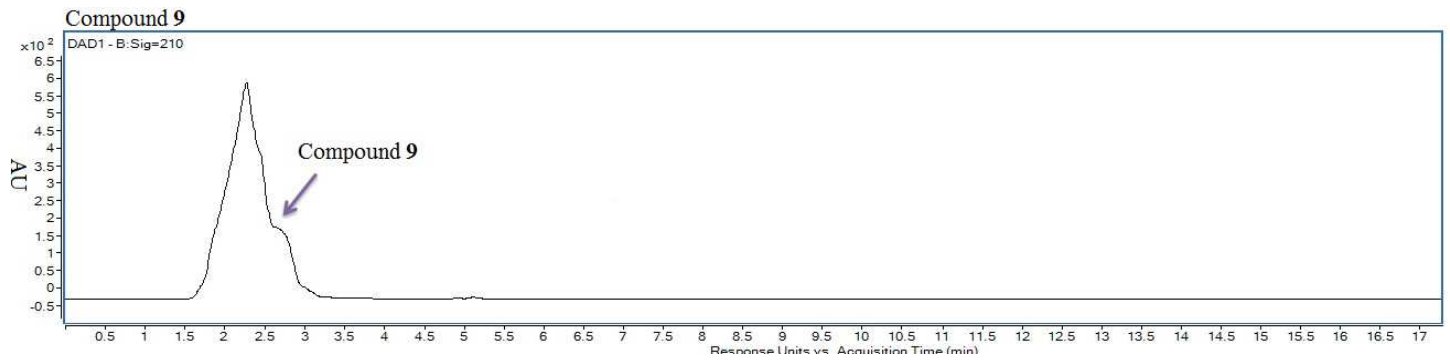

Compound $\mathbf{1 3}+$ Ascoribc $0 \mathrm{~h}$

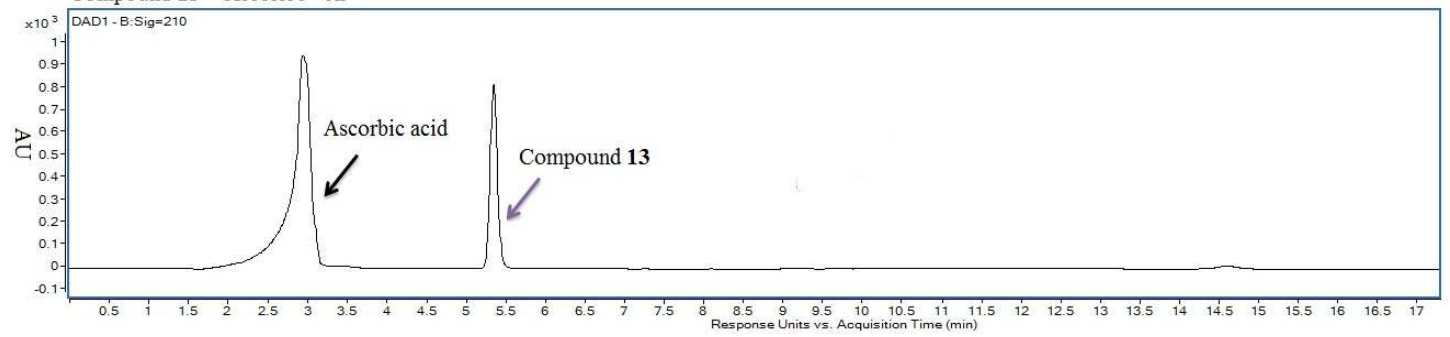

Compound $13+$ Ascoribc acid $1 \mathrm{~h}$

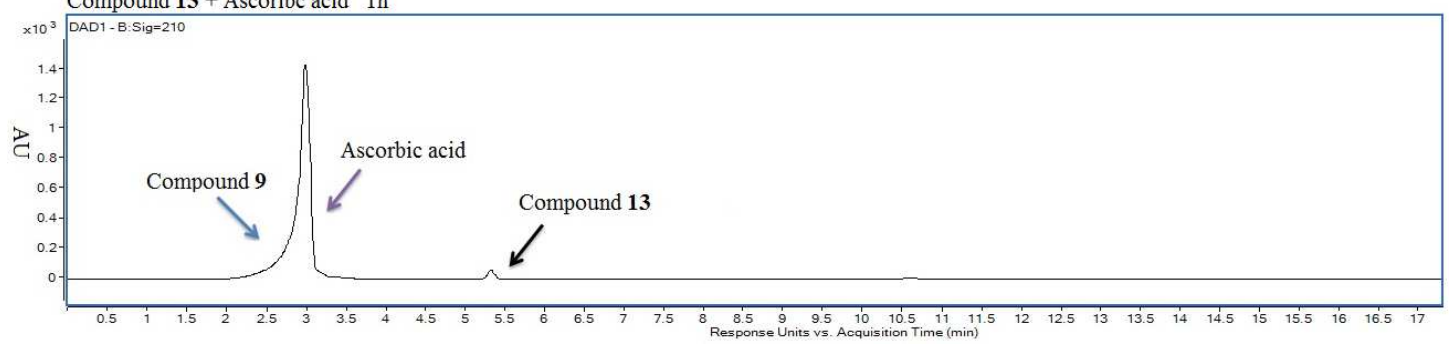

Compound $13+$ Ascorbic acid 2 h
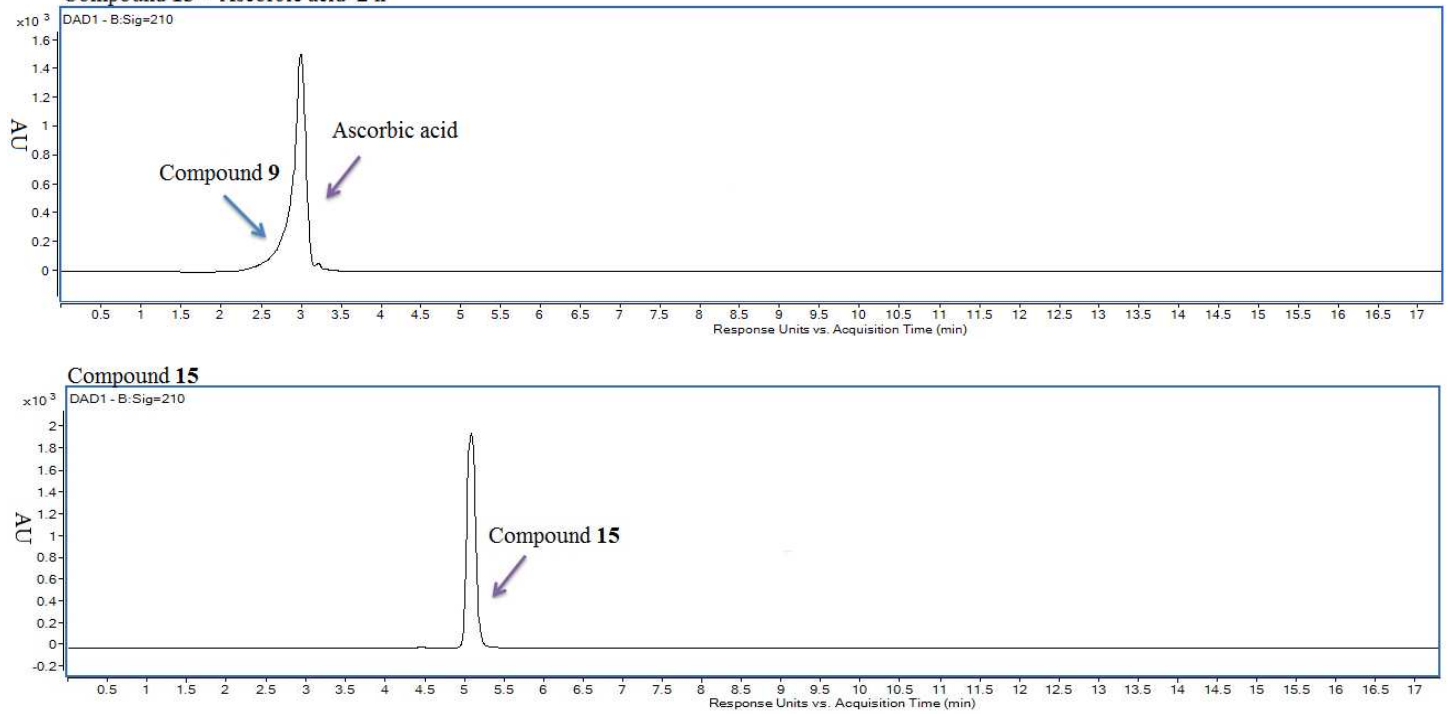

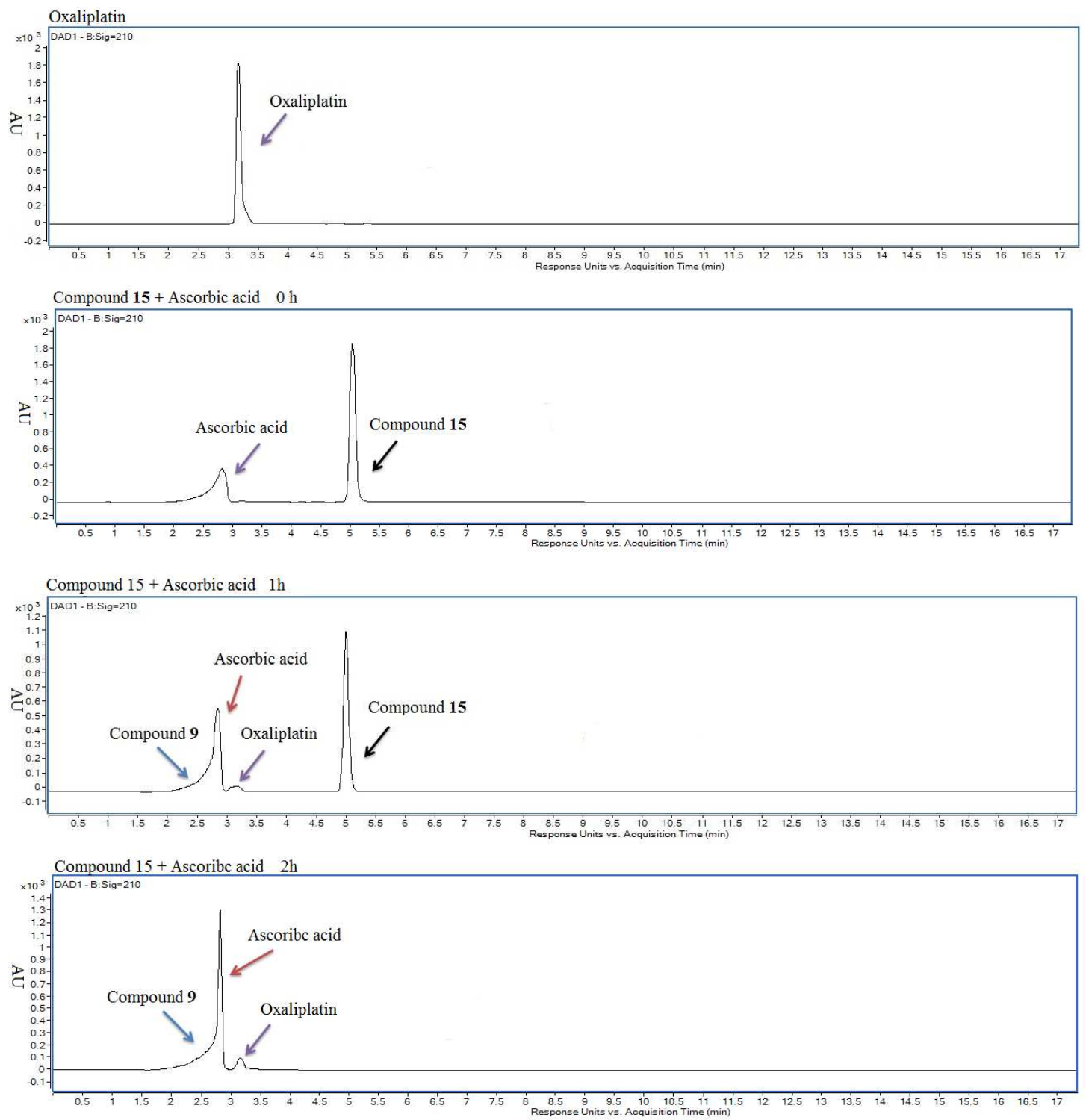

Figure S1. The released ability of $\mathrm{Pt}(\mathrm{IV})$ complexes under reduction with ascorbic acid.

\section{Binding mode of complexes 14, 15 and 9 .}
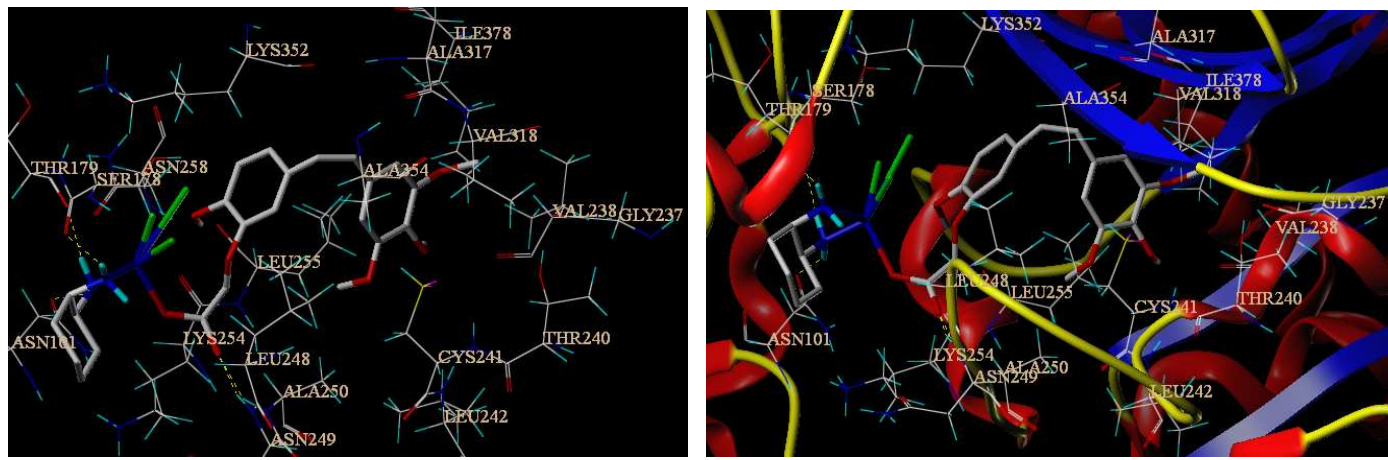

(14) 

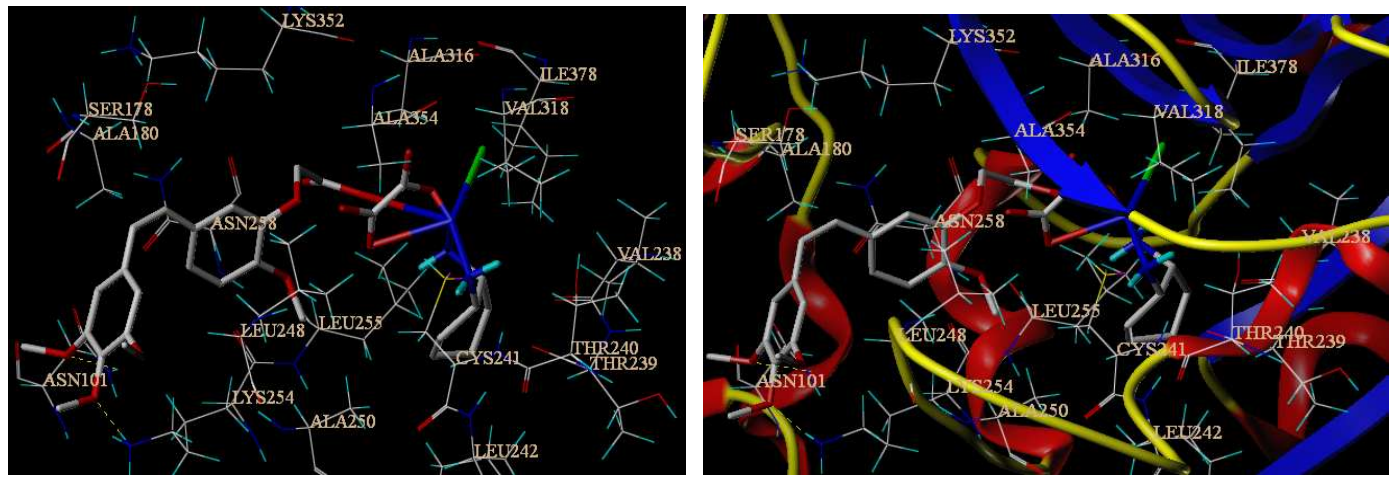

(15)
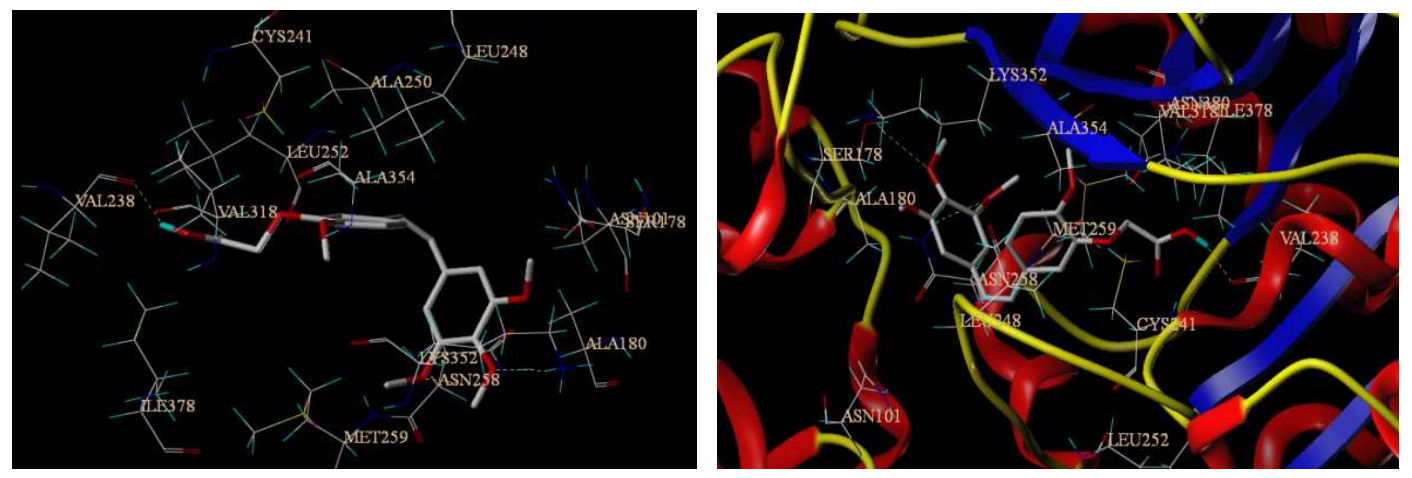

(9) 
3. ${ }^{1} H N M R,{ }^{13} C N M R$ and HR-MS of target compounds.

Compound 2.
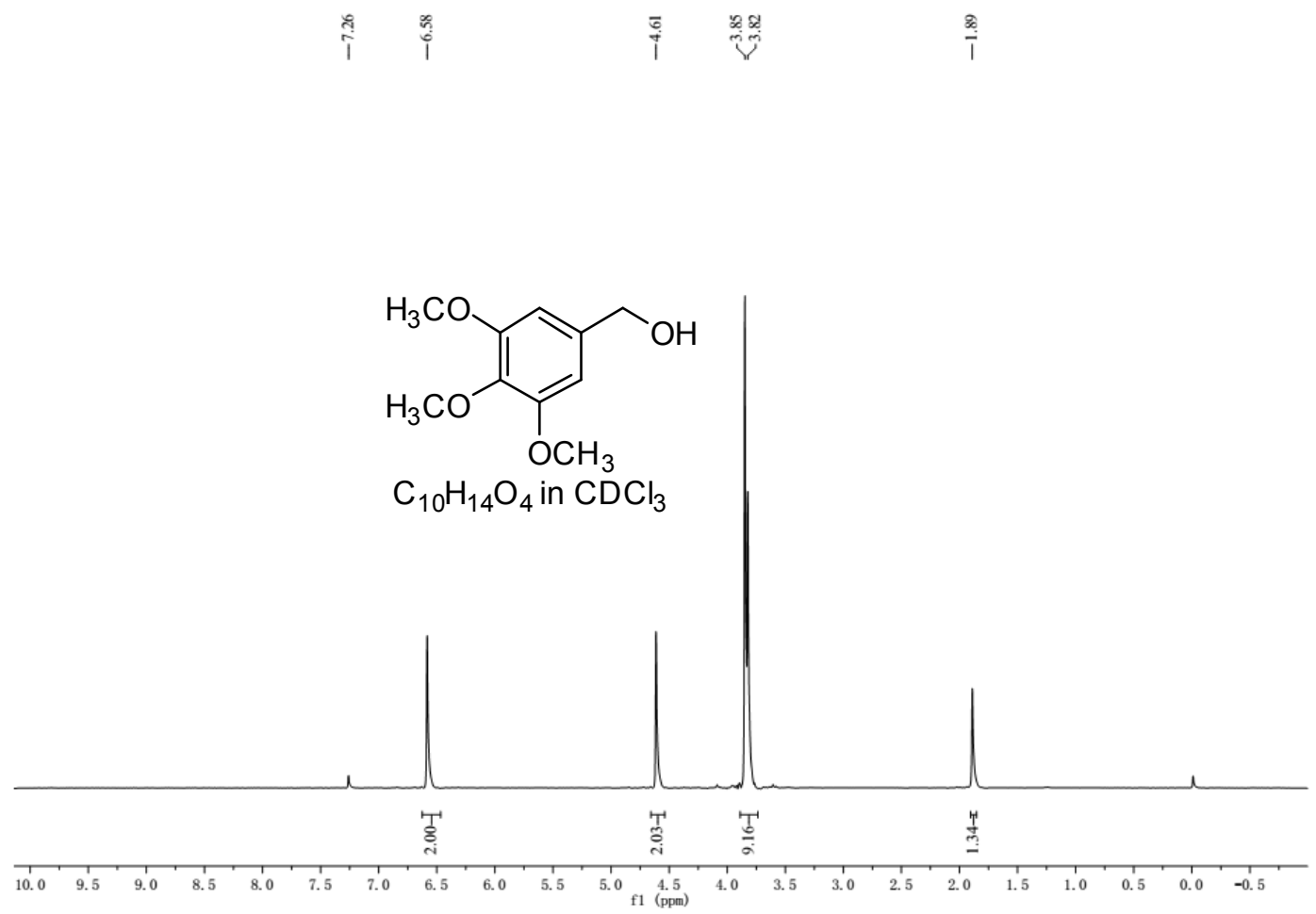
Compound 3.
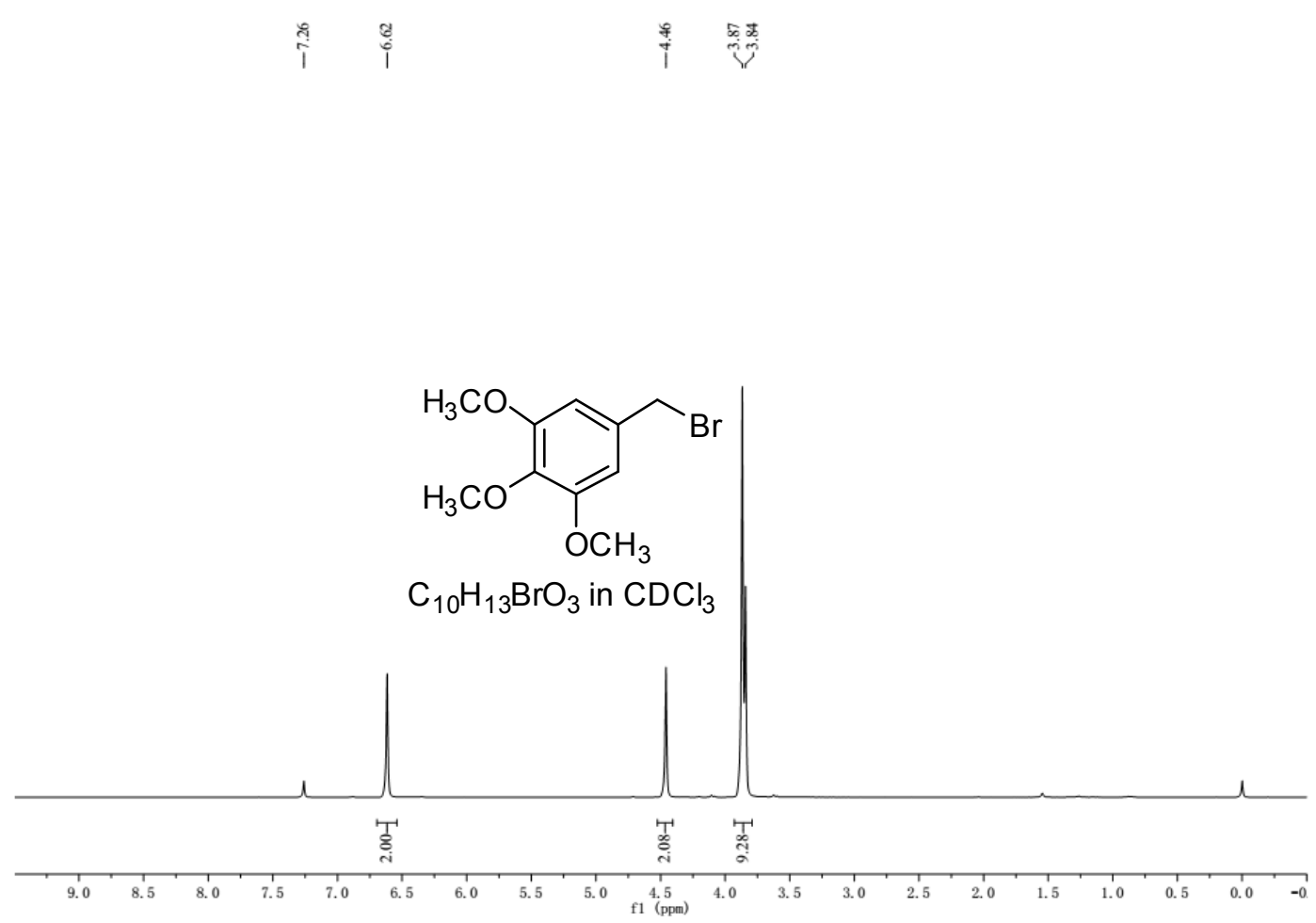


\section{Compound 4.}

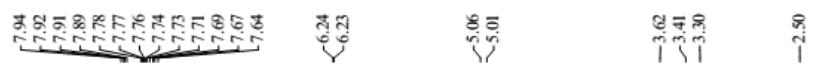

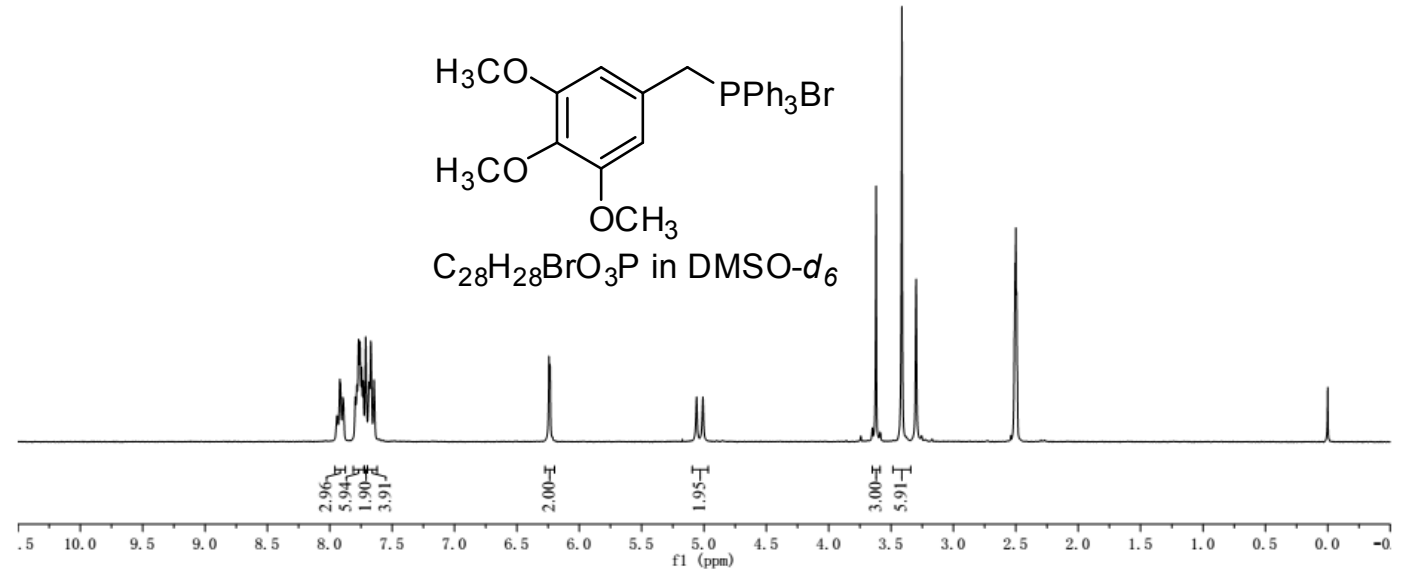

\section{Compound 5.}

i

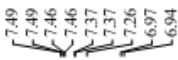

8

ए)

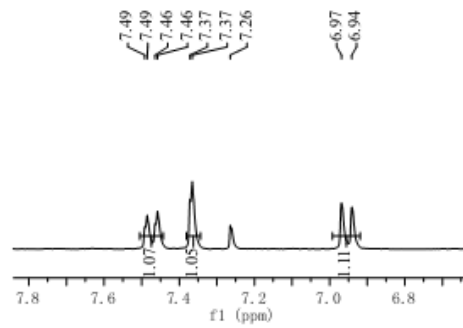<smiles>COc1ccc(C=O)cc1[O+]S(C)(=O)=O</smiles>

$\mathrm{C}_{14} \mathrm{H}_{22} \mathrm{O}_{3} \mathrm{Si}$ in $\mathrm{CDCl}_{3}$

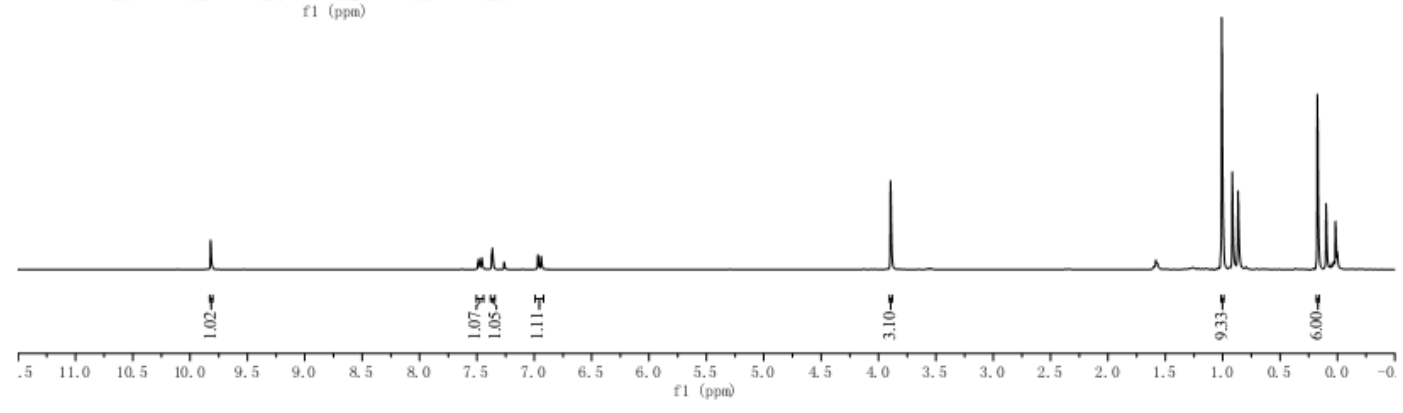




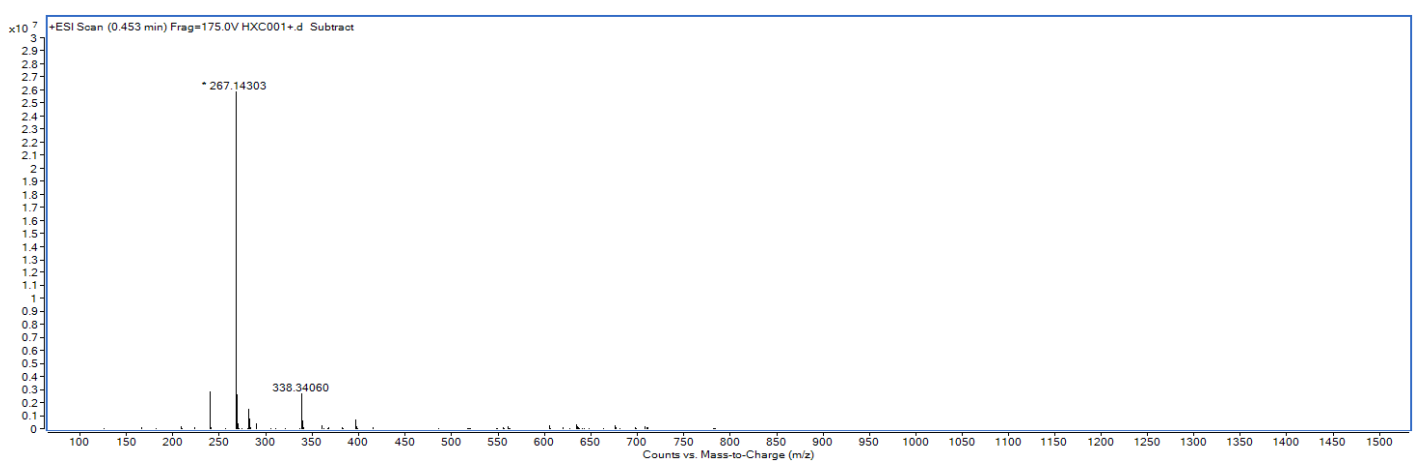

Compound 6a.
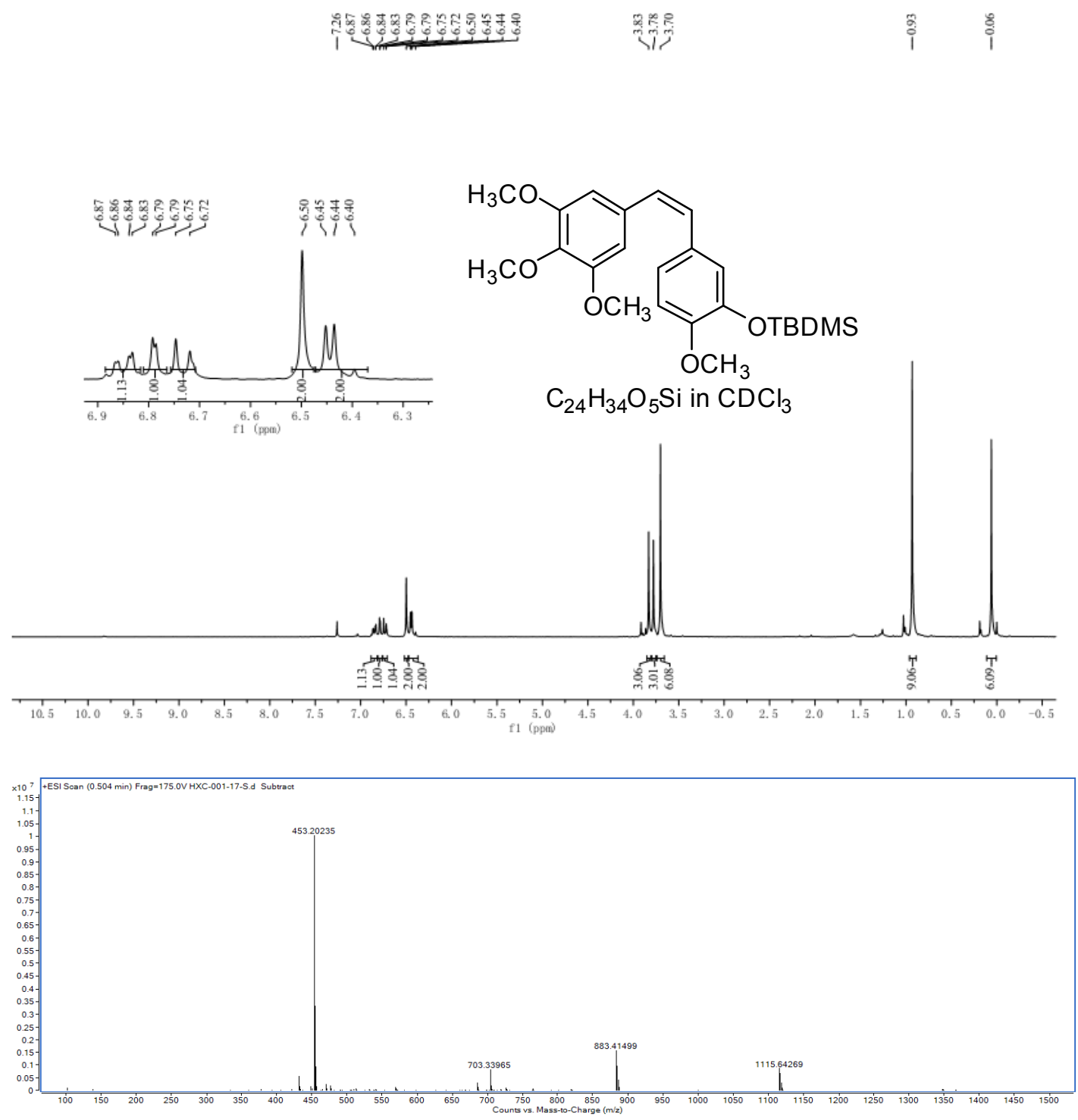
Compound 6b.

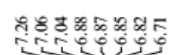

$\frac{2500}{217}$

$\stackrel{8}{i} \quad \stackrel{9}{i}$
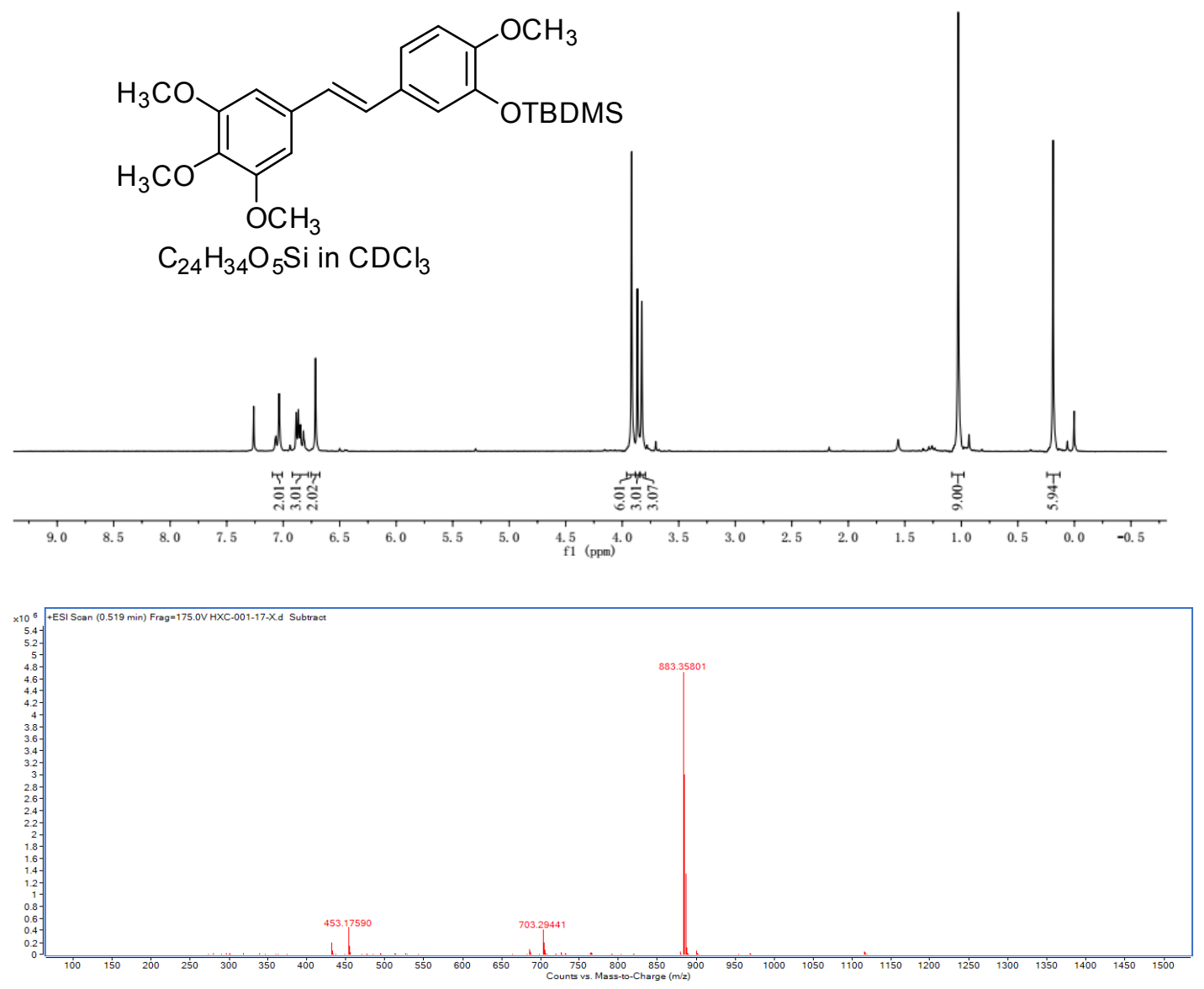


\section{Compound 7(CA-4).}
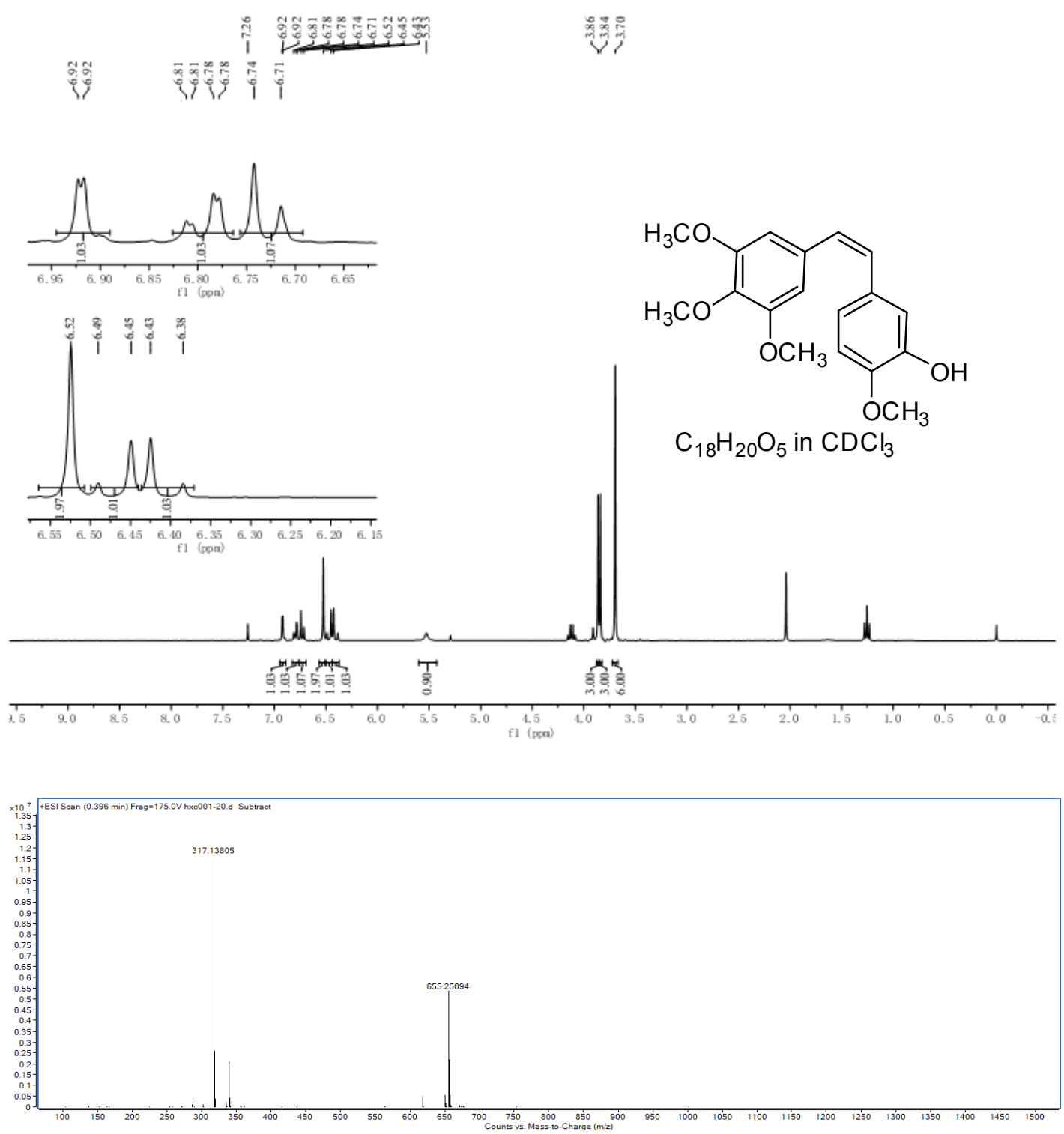


\section{Compound 8.}
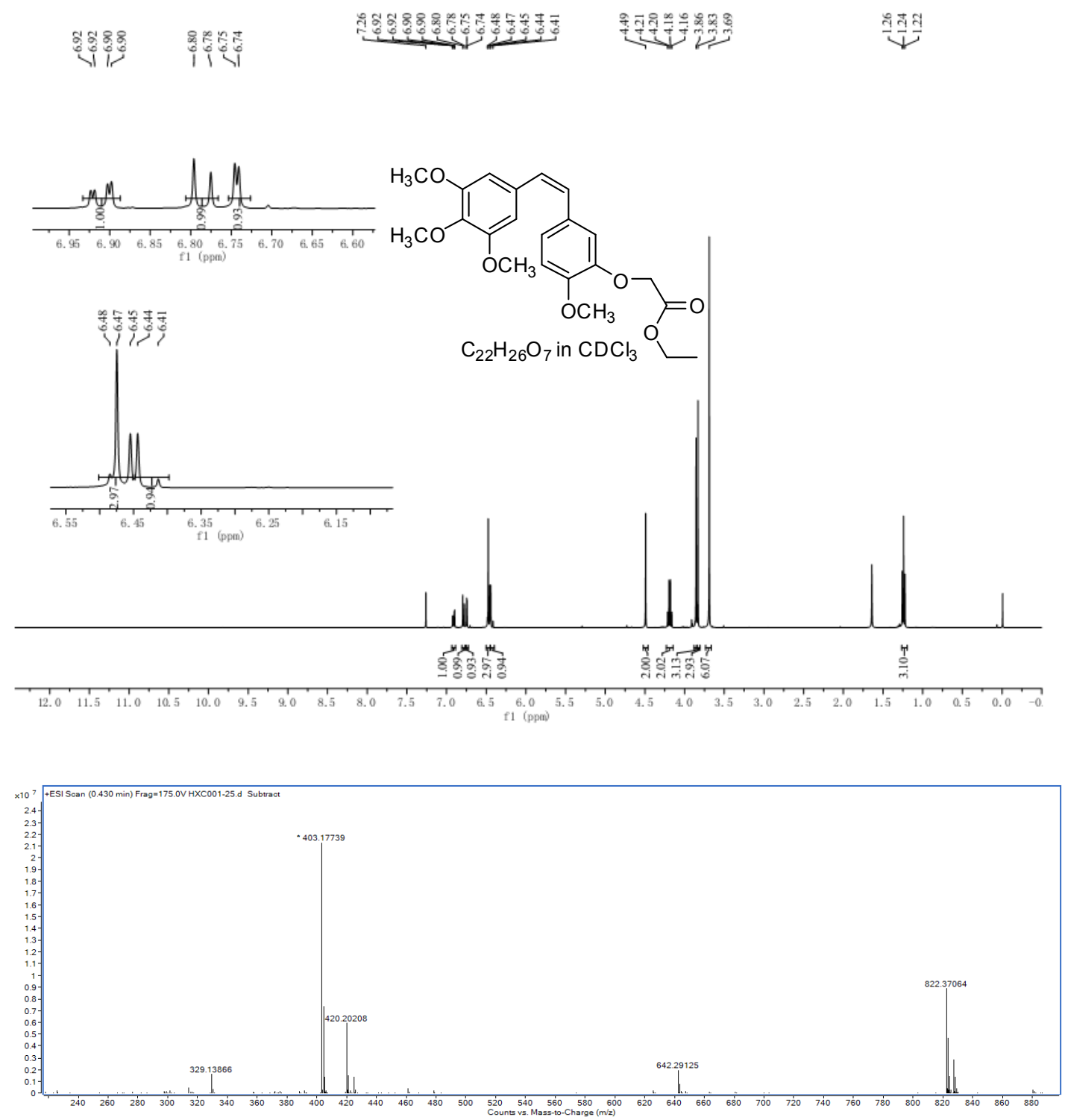


\section{Compound 9.}
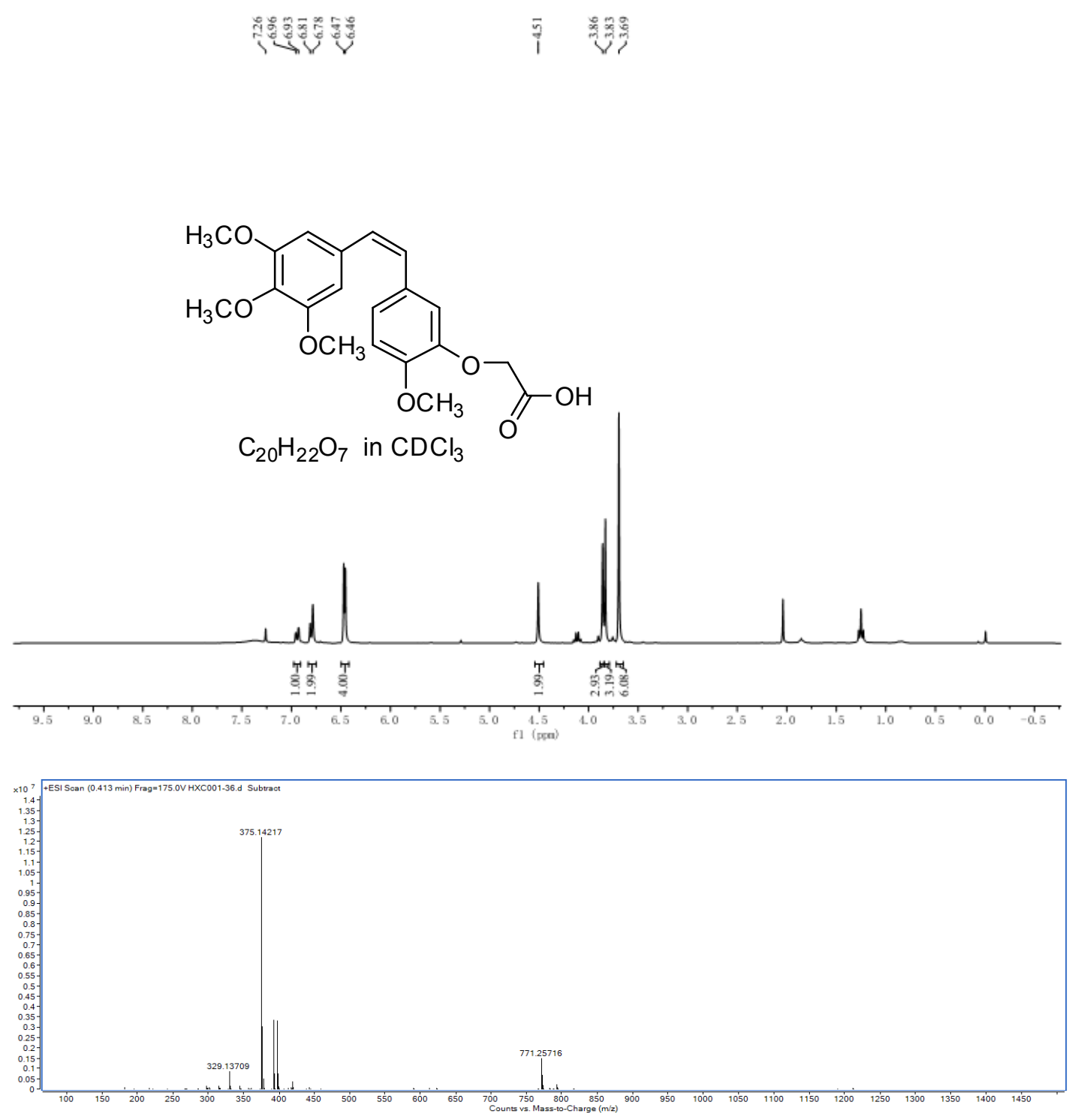


\section{Compound 10.}

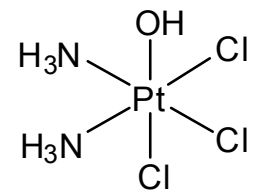

$\mathrm{H}_{7} \mathrm{~N}_{2} \mathrm{OPtCl}_{3}$ in DMSO-d6

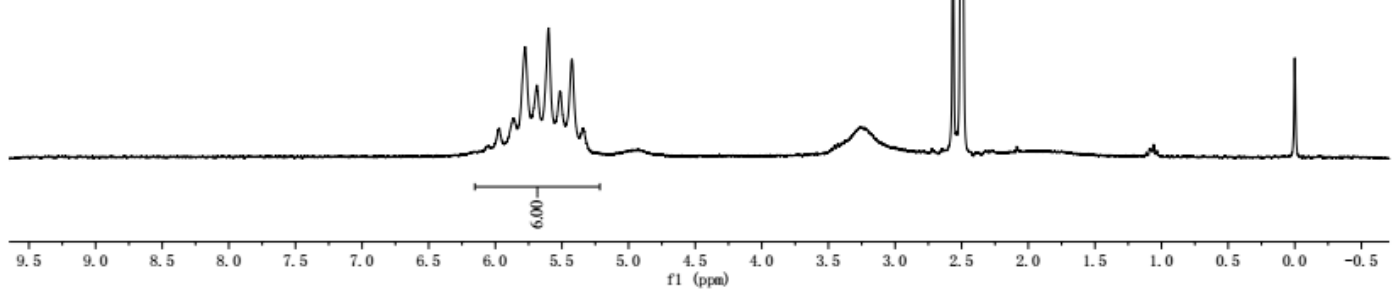

Compound 11.

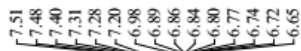

क

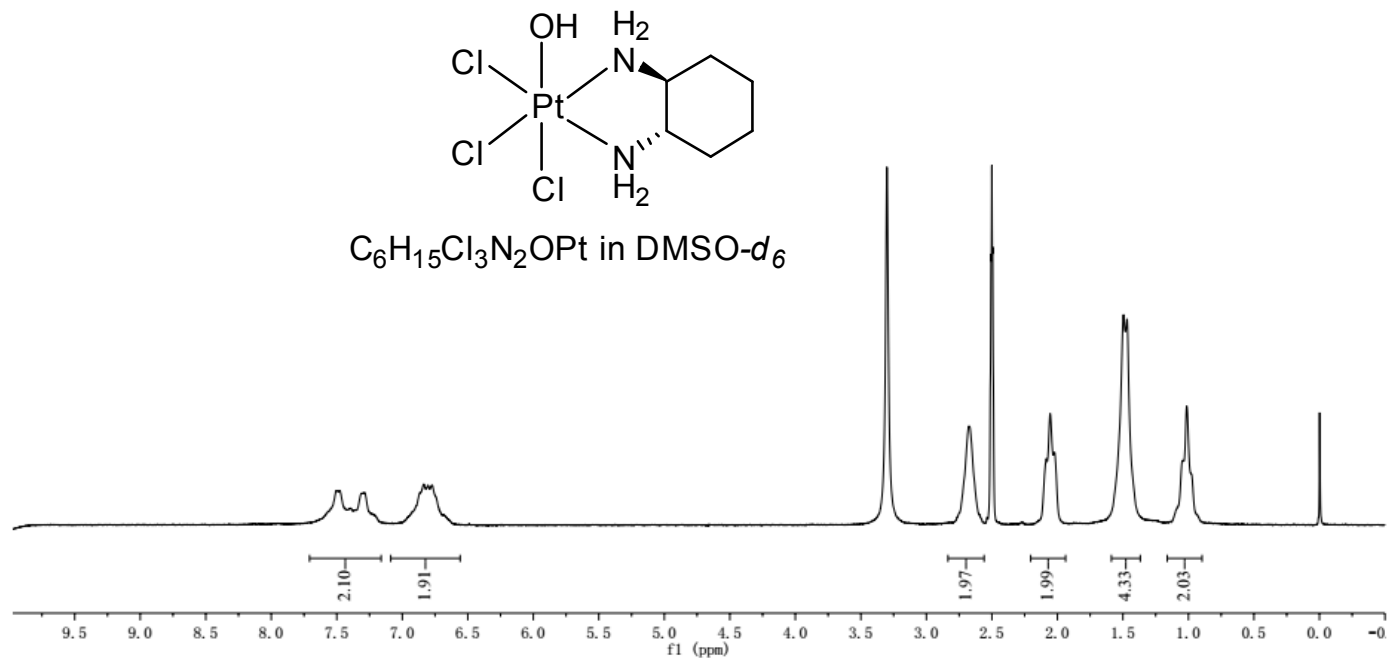


Compound 12.

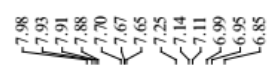

2.

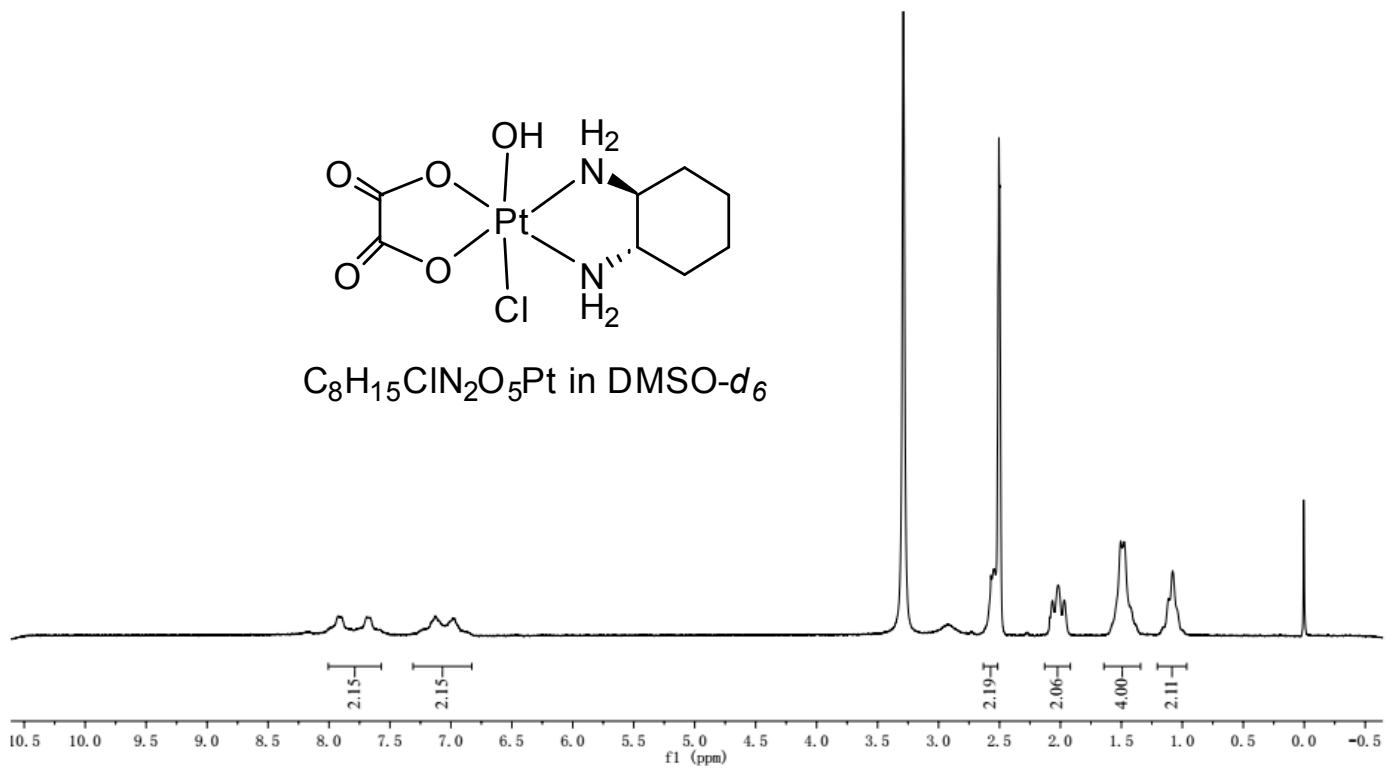


Compound 13.

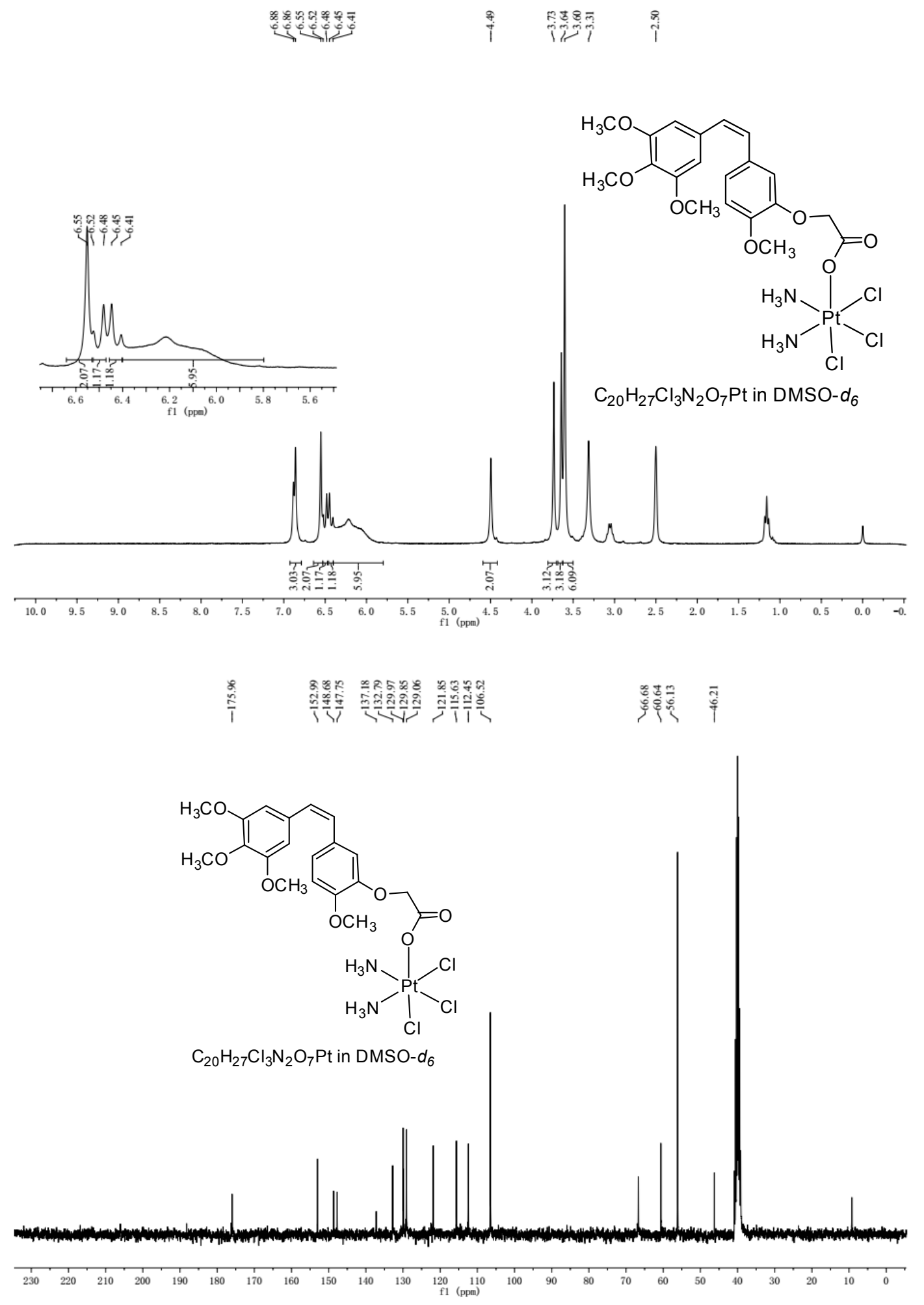




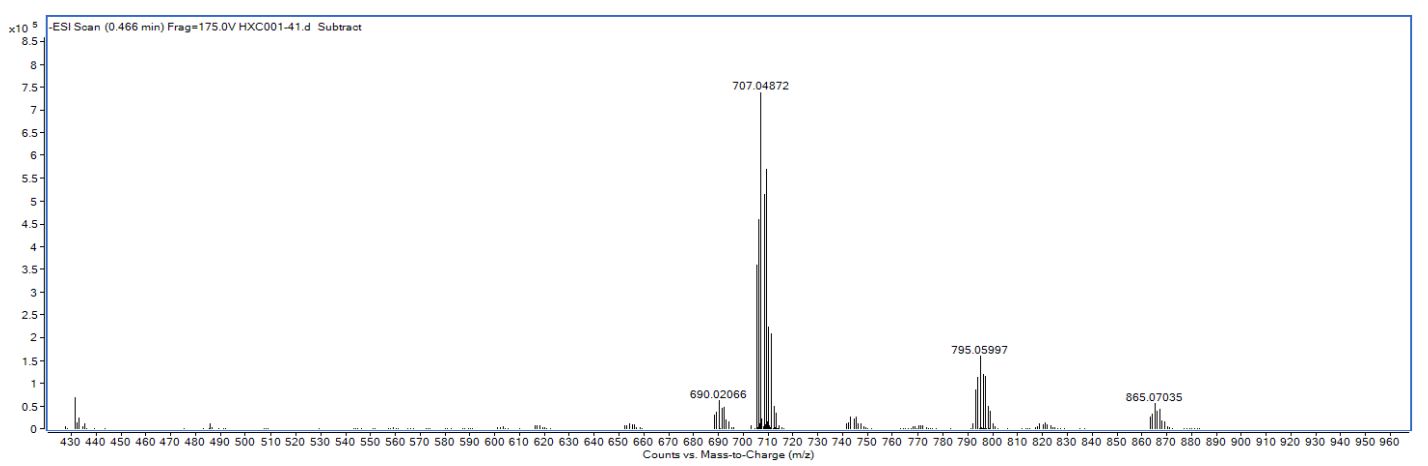




\section{Compound 14.}
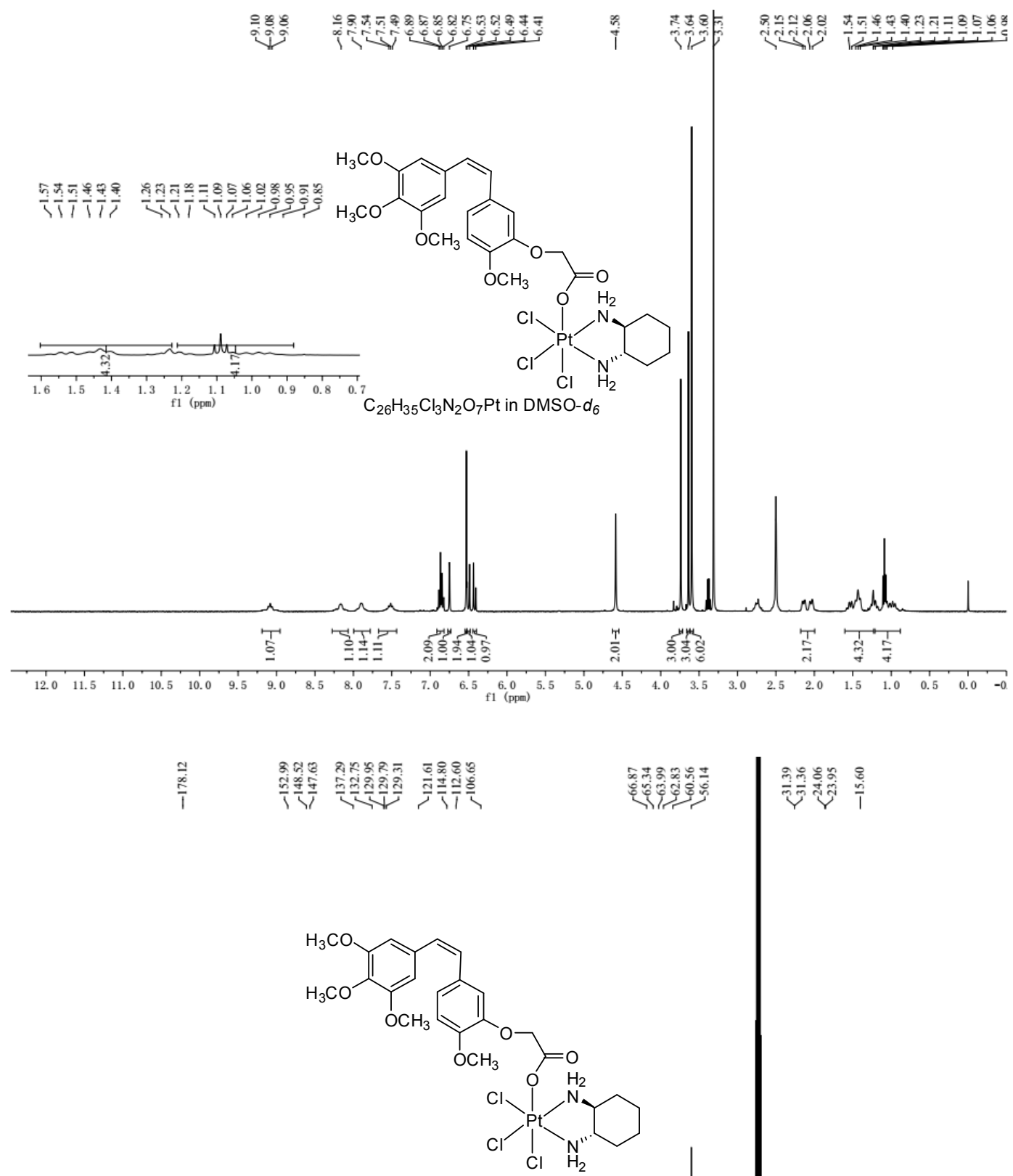

$\mathrm{C}_{26} \mathrm{H}_{35} \mathrm{Cl}_{3} \mathrm{~N}_{2} \mathrm{O}_{7} \mathrm{Pt}$ in DMSO- $d_{6}$
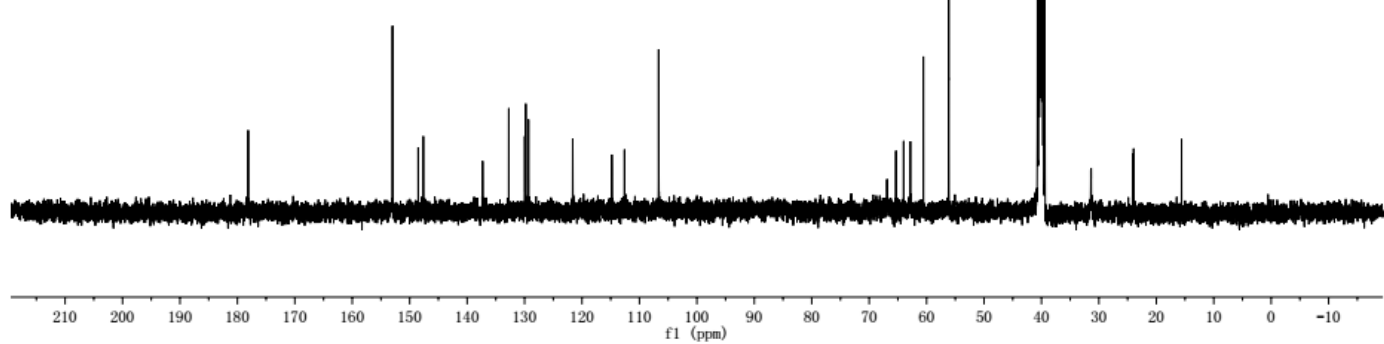


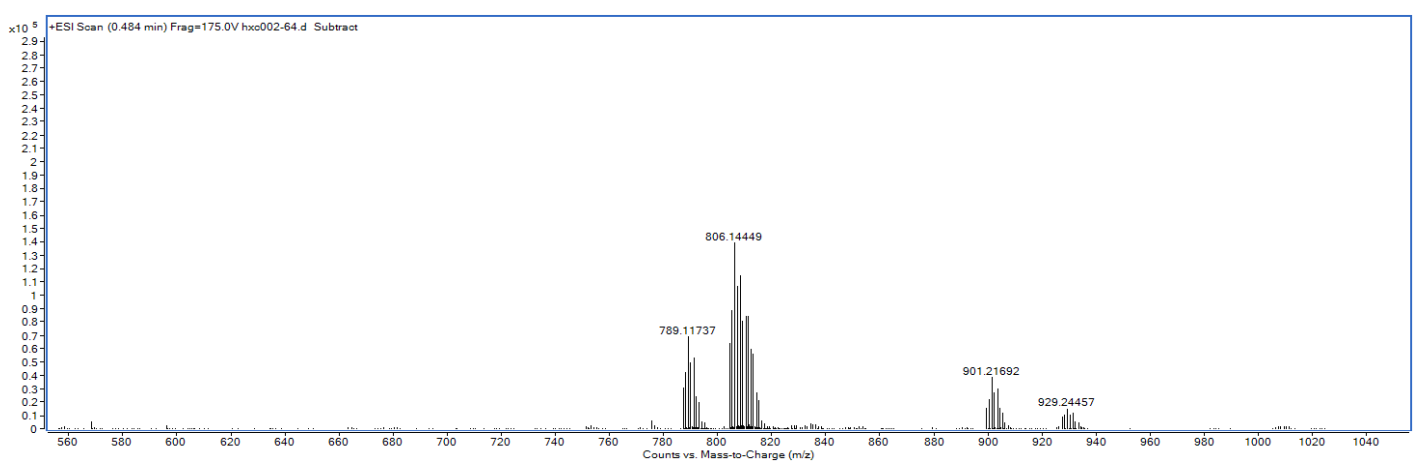

Compound 15.
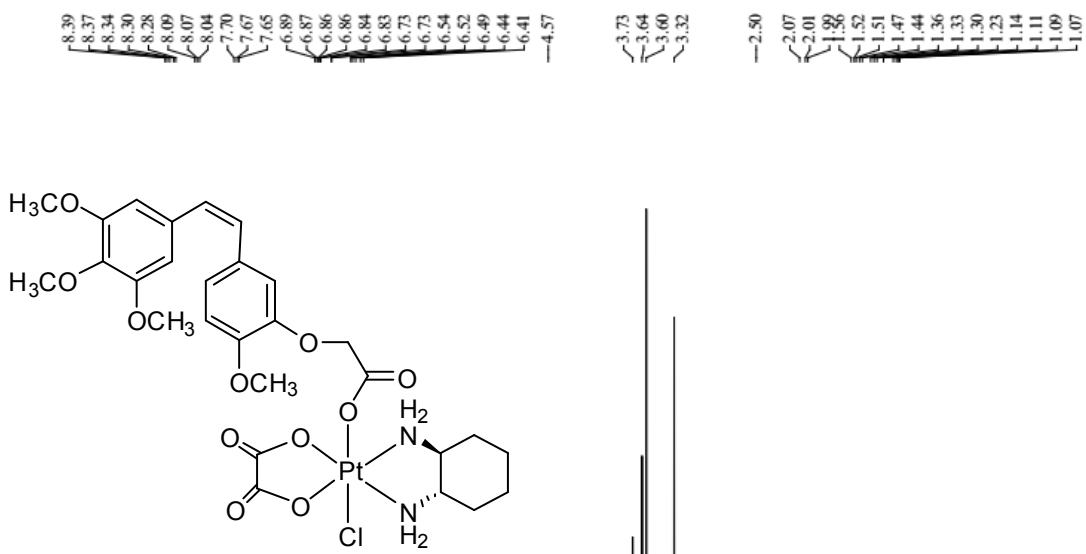

$\mathrm{C}_{28} \mathrm{H}_{35} \mathrm{CIN}_{2} \mathrm{O}_{11} \mathrm{Pt}$ in DMSO-d6

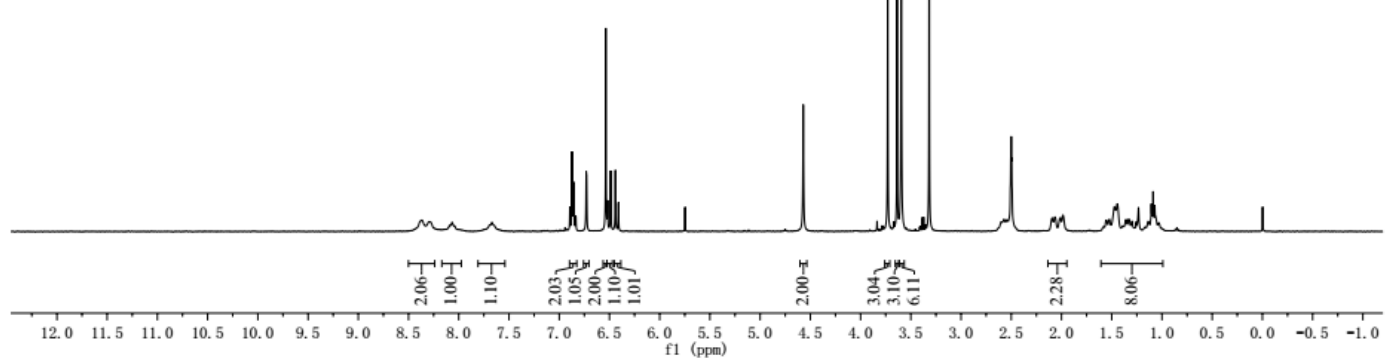



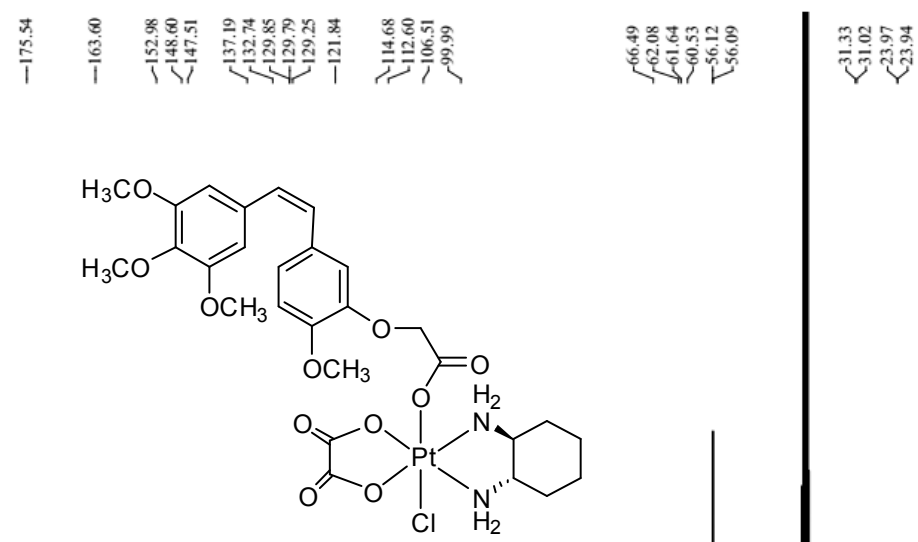

$\mathrm{C}_{28} \mathrm{H}_{35} \mathrm{CIN}_{2} \mathrm{O}_{11} \mathrm{Pt}$ in DMSO-d6
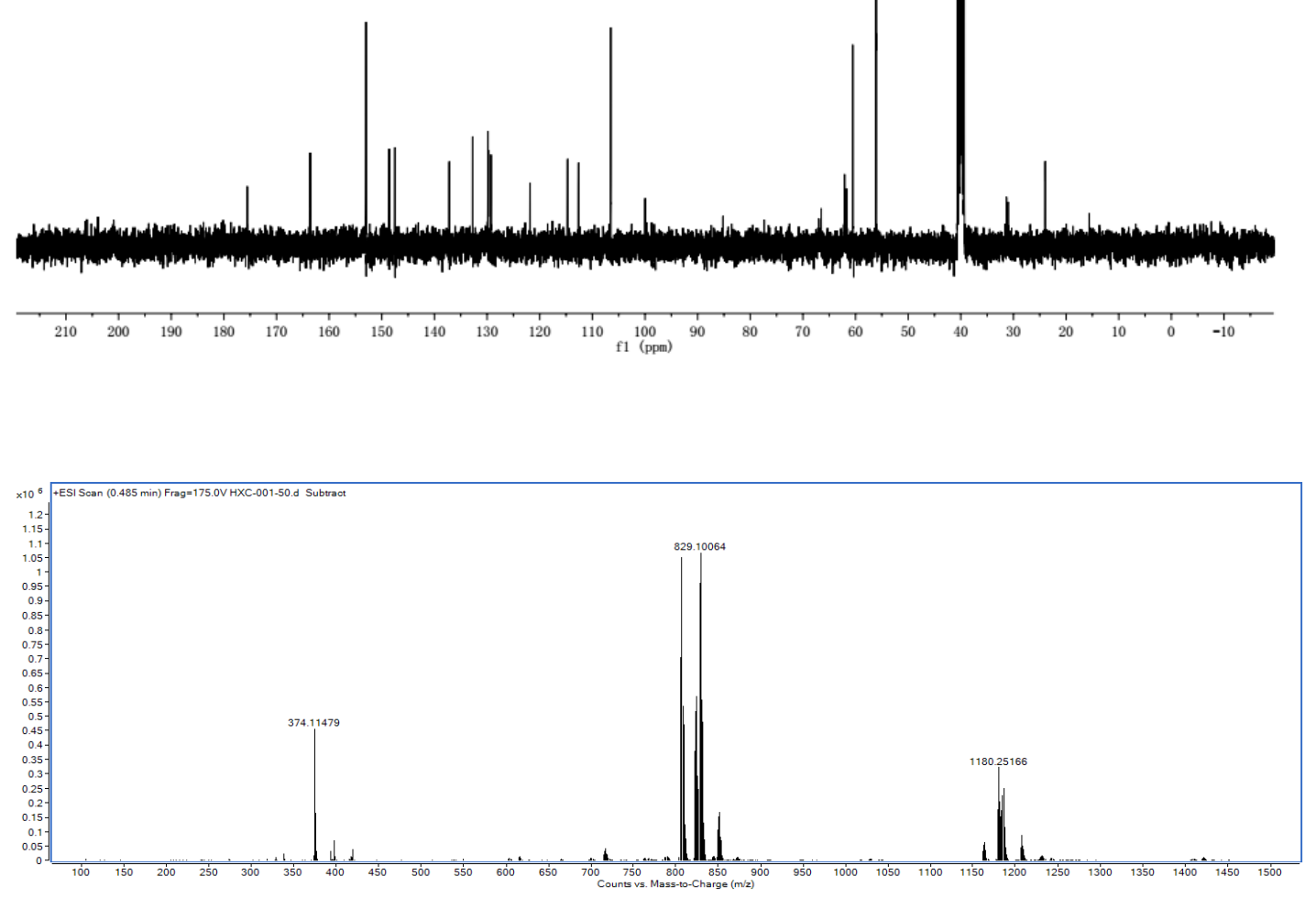